\title{
Spin-trapped Radicals: Determination by LC-TSP-MS and LC-ESI-MS
}

\author{
C. E. Parker, H. Iwahashi*, and K. B. Tomer \\ Laboratory of Molecular Biophysics, National Institute of Environmental Health Sciences, \\ Research Triangle Park, North Carolina, USA
}

The 4-POBN[ $\alpha$-(4-pyridyl-1-oxide)-N-tert-butyl-nitrone] radical adducts of ethyl and pentyl radicals were determined by a combination of high performance liquid chromatography (HPLC) combined with electron paramagnetic resonance (EPR) with HPLC-electrospray (ESI)-mass spectrometry and HPLC-thermospray (TSP)-MS. The identification of the peak corresponding to the spin-trapped radical was done by performing HPLC-EPR under the same chromatographic conditions as the HPLC-MS. The radical adducts could be determined by both techniques, even though for ESI only $12 \mu \mathrm{L} / \mathrm{min}$ of the total $1 \mathrm{~mL} / \mathrm{min}$ HPLC flow rate could be directed into the ion source. (J Am Soc Mass Spectrom 1991, 2, 413-418)

$\mathrm{T}$ o detect short-lived radicals, the spin-trapping technique was introduced [1] and has allowed the detection of many free radicals in biological systems. With the electron paramagnetic resonance (EPR) spin-trapping technique, determination of the structures has been based mainly on the hyperfine splitting pattern of the EPR spectra. Hyperfine coupling constants can give detailed information about the radical center but no information about the molecular weight. To obtain comprehensive knowledge about the structures of the radical adducts, additional information, such as that provided by mass spectrometry, is necessary.

Studies of radical adduct structures have used direct probe mass spectrometry [2-6] or gas chromatography combined with mass spectrometry (GC/MS) [7-12], usually after derivatization. Some radical adducts, however, are stable only in solution. High performance liquid chromatography mass spectrometry (HPI.C-MS) offers the advantage of keeping the radicals in solution at least until they enter the ion source.

Several research groups have used HPLC-EPR for the observation of spin-trapped radicals [13-16]. As a continuation of our interest in the determination of spin-trapped radicals, we have combined HPLC-EPR with thermospray (TSP) mass spectrometry (HPLCTSP-MS) and demonstrated its use in the determination of DMPO (5,5-dimcthyl-1-pyrroline $\mathrm{N}$-oxide)

\footnotetext{
*Present address: Department of Chemistry, Wakayama Medical College, Wakayama-shi, Wakayama-ken, Japan.

Address reprint requests to K. B. Tomer, Laboratory of Molecular Biophysics, National Institute of Environmental Health Sciences, P.O. Box 12233, Research Triangle Park, NC 27709.
}

adducts with hydroxymethyl, $\alpha$-hydroxyethyl, and hydroxyl radicals [17]. Subsequently, enzymatically generated radicals of linoleic, linolenic, and arachidonic acid, trapped with nitrosobenzene and 2methyl-2-nitrosopropane (MNP) were studied [18]. On the basis of the liquid chromatography combined with mass spectrometry (LC-MS) data in conjunction with the HPLC-EPR data, the structure of the carboncentered radical from linoleic acid was determined to be 12,13-epoxylinoleic acid radical rather than the previously assumed linoleic acid radical.

Another ionization technique that is compatible with LC separation and sample introduction is electrospray ionization (ESI). Electrospray ionization is a relatively new mass spectral technique in which small, highly charged droplets are generated by passing a solvent stream through a needle at high voltage [19]. Sample ions are formed from the droplets, probably by an ion evaporation mechanism [20]. Electrospray (or ion spray, nebulization-assisted electrospray [21]) is a very gentle ionization technique and has been used for the successful analysis of a wide variety of compound types, including proteins and peptides [22-24], drugs [25, 26], pesticides [26], azo dyes [26], and marine neurotoxins [27, 28].

Wc have expanded our studies of the combination of HPLC-EPR and HPLC-MS for determination of radical spin adducts to include ESI-MS as well as TSP-MS techniques. In this article we present the results of a comparative study of the use of the two ionization techniques for the determination of a new set of radical adducts: ethyl and pentyl radicals trapped with 4-POBN ( $\alpha$-(4-pyridyl-1-oxide)- $N$-tertbutyl-nitrone). 


\section{Experimental}

\section{Preparation of Ethyl and Pentyl Radicals}

Ethyl and pentyl radical adducts of 4-POBN were prepared via the decomposition of ethyl hydrazine and pentyl hydrazine, respectively [12]. To $5 \mathrm{~mL}$ of a 0.05-M ammonium carbonate buffer ( $\mathrm{pH} 10.0$ ), purged by bubbling with nitrogen gas, was added ethyl- or pentyl-hydrazine oxalate (120 mg), $50 \mathrm{mg} 4-\mathrm{POBN}$, and $0.5 \mathrm{~mL}$ of $2 \mathrm{mM} \mathrm{CuCl}{ }_{2}$. The reactions were allowed to continue for $2 \mathrm{hr}$ at $25^{\circ} \mathrm{C}$ in air. The reaction mixtures were dried under reduced pressure, and redissolved in $4 \mathrm{~mL} \mathrm{20:80} \mathrm{methanol:10} \mathrm{mM} \mathrm{am-}$ monium acetate. Four $1 \mathrm{~mL}$ samples were applied to the HPLC-EPR system, a Waters $\mu$-Bondapak C18 column (30 cm length $\times 4.6 \mathrm{~mm}$ id) (Waters Chromatography, Division of Millipore, Milord, MA), and the peaks that gave EPR signals (see below) were collected and combined. A 1-mL aliquot containing the partially purified radical adduct was reapplied to the HPLC column for the on-line HPLC-EPR and HPLC-MS analyses.

\section{HPLC-EPR}

HPLC-EPR spectroscopy was performed by using an HPLC system equipped with EPR detection as described previously $[12,17,18]$. HPLC-EPR was performed by using a Waters model $6000 \mathrm{~A}$ solvent delivery system with a Varian E-104 EPR spectrometer (Varian Associates, Sugarland, TX). The EPR spectrometer was connected to the HPLC by a teflon tube that passed through the EPR cell. The magnetic field of the EPR spectrometer was fixed at the lowest field of the six line signals detected from 4-POBN radical adducts $\left(\mathrm{a}^{\mathrm{N}}=15.8 \mathrm{G}\right.$ and $\left.\mathrm{a}_{\beta}^{\mathrm{H}}=2.6 \mathrm{G}\right)$. HPLC column conditions were as follows: flow rate, $1.0 \mathrm{~mL} / \mathrm{min}$; injection volume, $1.0 \mathrm{~mL}$; gradient elution [solvent $A$, $10 \mathrm{mM}$ ammonium acetate, $20 \%$ acetonitrile $(\mathrm{v} / \mathrm{v})$; solvent $B, 10 \mathrm{mM}$ ammonium acetate, $80 \%$ acetonitrile $(\mathrm{v} / \mathrm{v})$; programmed from $20 \%$ to $70 \% \mathrm{~B}$ in $30 \mathrm{~min}]$. The UV detector was set at $280 \mathrm{~nm}$, at a sensitivity setting of 1 afs. The EPR settings were: microwave power, $20 \mathrm{~mW}$; modulation amplitude, $8 \mathrm{G}$; modulation frequency, $100 \mathrm{kHz}$; time constant, $1 \mathrm{~s}$; receiver gain, $5 \times 10^{2}$.

\section{LC-TSP-MS and LC-ESI-MS}

The same mobile phase and the same HPLC column were used for the HPLC-EPR and the HPLC-MS experiments. The mass spectrometer used for both the HPLC-TSP-MS and HPLC'ESI-MS experiments was a VG 12-250 mass spectrometer/data system (VG Masslab, Altrincham, UK). In both cases the mass range scanned was 100 to $500 \mathrm{u}$ at $2 \mathrm{~s}$ per scan, and identical multiplier settings were used.

The source used for the TSP experiments was a Vestec 701S thermospray source (Vestec Corp., Houston, TX). Operating conditions were: control tempera- ture (T1), $72{ }^{\circ} \mathrm{C}$; tip temperature, $249^{\circ} \mathrm{C}$; vapor temperature, $215{ }^{\circ} \mathrm{C}$; block temperature, $297{ }^{\circ} \mathrm{C}$; tip heater, $252^{\circ} \mathrm{C}$; lens, $29^{\circ} \mathrm{C}$. The discharge was on and read $200 \mu \mathrm{amp}$. The repeller was set for positive ions, at $0 \mathrm{~V}$.

The source used for the ESI experiments was a Vestec electrospray source, model 611B. Operating conditions were: needle voltage, $3.08 \mathrm{kV}$; spray current, $0.234 \mu \mathrm{a}$; block temperature, $262{ }^{\circ} \mathrm{C}$; chamber temperature, $51^{\circ} \mathrm{C}$; skimmer voltage, $14 \mathrm{~V}$. The Vestec ESI interface differs from those of other manufacturers by the absence of a nitrogen curtain gas and the use of a heated block for declustering (similar to Vestec's thermospray source design). The probe used was one developed in this laboratory for capillary zone electrophoresis (CZE)/MS, and was of coaxial flow design [29]. Coaxial flow allows the delivery of make-up solution to the probe tip without loss of chromatographic resolution. The coaxial flow concept was originally developed for postcolumn derivatization with capillary columns [30]. For the work described here, the probe was operated with $5 \mu \mathrm{L} / \mathrm{min}$ sheath flow (50:50 MeOH: $3 \%$ aqueous acetic acid) and $12 \mu \mathrm{L} / \mathrm{min}$ sample flow.

The sample stream was split off the $1 \mathrm{~mL} / \mathrm{min}$ HPLC column effluent after the UV detector and entered the source via a 1.1-m length of $75 \mu \mathrm{m}$ id $\times 150$ $\mu \mathrm{m}$ od fused silica capillary tubing, previously treated with aminopropyl silane [31]. The ESI: waste flow rate ratio was set by adjusting the flow through a Valco "tee" (VICI-Valco Instrument Co., Inc., Houston, TX) with a Nupro needle valve (Willoughby, $\mathrm{OH}$ ) on the "waste" line, similar to the splitting system used in direct liquid introduction LC-MS [32].

\section{Results and Discussion}

The results of the TSP and ESI experiments on the POBN-ethyl radical adduct are shown in Figure 1 . The prominent peak in the reconstructed ion chromatogram (RIC) for $m / z 224$ in the TSP analysis corresponds to the POBN-ethyl radical adduct as determined by HPLC-EPR. An ion of $m / z 224$ in the ESI experiment also shows a peak at the same retention time as the POBN radical adduct, as determined by HPLC-EPR. Spectra obtained from the POBN-ethyl radical adduct by 'ISP and ESI are shown in Figure 2 . Although the mass spectrum is averaged and background subtracted (from the chromatographic analysis), reasonable single scan data can be obtained. 'The ion at $m / z 224$ corresponds to the $[\mathrm{M}+\mathrm{H}]^{+}$ion for the expected structure of the POBN-ethyl spin-trapped radical [12]. Ions are often observed as multiple peaks due to the broad electrospray peak shape and the centroiding algorithm used in data acquisition. The nonradical component observed in the RIC of $\mathrm{m} / \mathrm{z}$ 224 is of unknown structure. Its mass spectrum shows a protonated molecular ion of $m / z 223(100 \%$ relative abundance) and an ion due to loss of $\mathrm{C}_{4} \mathrm{H}_{8}(\mathrm{~m} / \mathrm{z} 167$, $30 \%$ relative abundance). 

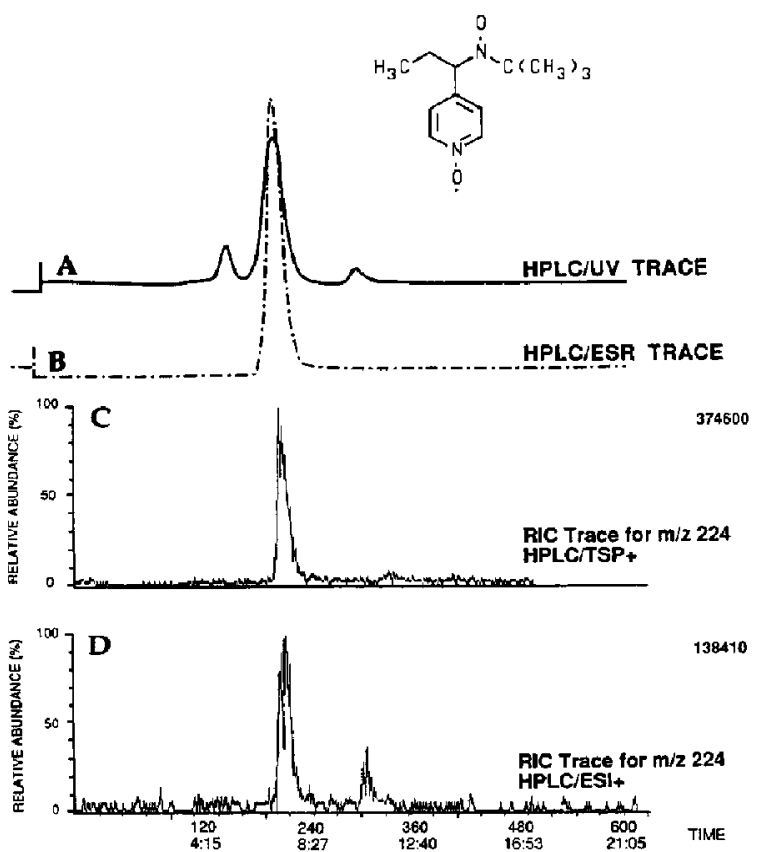

Figure 1. POBN-ethyl radical adduct. (A) HPLC-UV trace; (B) HPLC-EPR trace; (C) HPLC-TSP-MS, reconstructed ion chromatogram for $m / z$ 224; (D) HPLC-ESI-MS, reconstructed ion chromatogram for $m / z 224$.

Results for the POBN-pentyl radical adduct are shown in Figure 3. Peaks near 16 min retention time in the RIC traces for $m / z 266$ in the TSP and ESI analyses correspond to the POBN-pentyl radical adduct as determined by HPLC-EPR experiments. In the TSP and ESI spectra of the POBN-pentyl radical adduct (Figure 4, averaged, background subtracted), the ion of $m / z 266$ corresponds to the $[\mathrm{M}+\mathrm{H}]^{+}$ion for the spin-trapped radical [33]. The unknown nonradical component in the RIC of $\mathrm{m} / z 266$ near $13 \mathrm{~min}$ retention time shows a protonated molecular ion of $m / z 265$ and an ion due to $\mathrm{C}_{4} \mathrm{H}_{8}$ loss at $\mathrm{m} / z 209$ ( $40 \%$ relative abundance). The second nonradical component near $22 \mathrm{~min}$ gave a virtually identical spectrum.

A comparison of the TSP and ESI spectra shows basically the same ions but of differing relative abundances, with ESI giving greater molecular ion relative abundance than does TSP. The ESI spectra also show $\left[\mathrm{M}+\mathrm{Na}^{+}{ }^{+}\right.$ions of fairly low relative abundance. TSP gives more fragmentation, but the major fragmentation pathway is the same: loss of the $\operatorname{NOC}\left(\mathrm{CH}_{3}\right)_{3}$ group to give $[\mathrm{M}+\mathrm{H}-87]^{+}$at $m / z \quad 137$ in the POBN-ethyl spectrum and $m / z 179$ in the POBNpentyl spectrum. The loss of $87 \mathrm{u}$ from the $\mathrm{M}^{+}$ion has also been observed in the electron impact mass spectrum of the POBN-phenelzine radical [8].

The TSP spectrum of the pentyl radical also shows additional fragments that can be interpreted as loss of $\mathrm{C}_{4} \mathrm{H}_{9}$ (from the pentyl side chain) either from the molecular ion (to give $m / z 209$ ) or from the $m / z 179$ ion (to give $m / z$ 122). The ions of $m / z 136$ in both the ESI and TSP spectra can be interpreted as loss of $\mathrm{C}_{3} \mathrm{H}_{7}$ (from the pentyl side chain) from the $\mathrm{m} / \mathrm{z} 179$ ion. In the TSP spectrum, losses of $O$ from the molecular ion (to give $m / z$ 250), from the $m / z 179$ ion (to give $m / z$ 163), and from the $m / z 209$ (to give $m / z$ 193) are also observed. These ions were not observed in the ESI spectrum and may be due to thermal processes. These pathways are shown in Scheme I. Detailed studies of the fragmentation pathways, however, are not possible without tandem mass spectrometry data.

\section{Sensitivity Comparison}

The TSP results were obtained with approximately 80 times as much analyte entering the mass spectrometer source as was used in the ESI experiments $(12 \mu \mathrm{L} / \mathrm{min}$
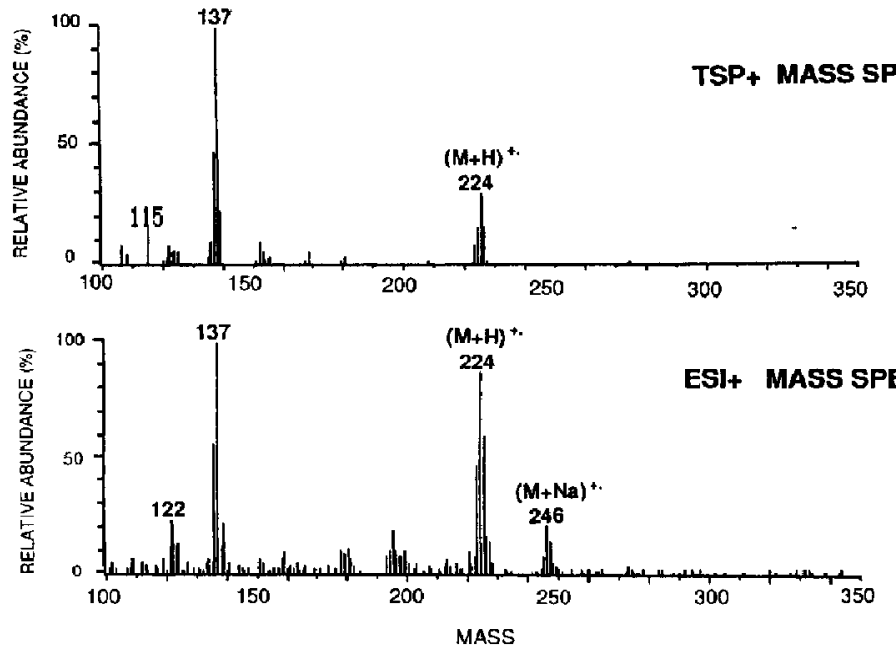

Figure 2. TSP and ESI mass spectra for the POBN-ethyl radical adduct (obtained from the HPLC-TSP-MS and HPLC-ESIMS analyses shown in Figure 1). 
Figure 3. POBN-pentyl radical adduct. (A) HPLC-UV trace; (B) HPLC-EPR trace; (C) HPLC-TSP-MS, reconstructed ion chromatogram for $m / z$ 266; (D) HPLC-ESI-MS, reconstructed ion chromatogram for $\mathrm{m} / \mathrm{z}$ 266.

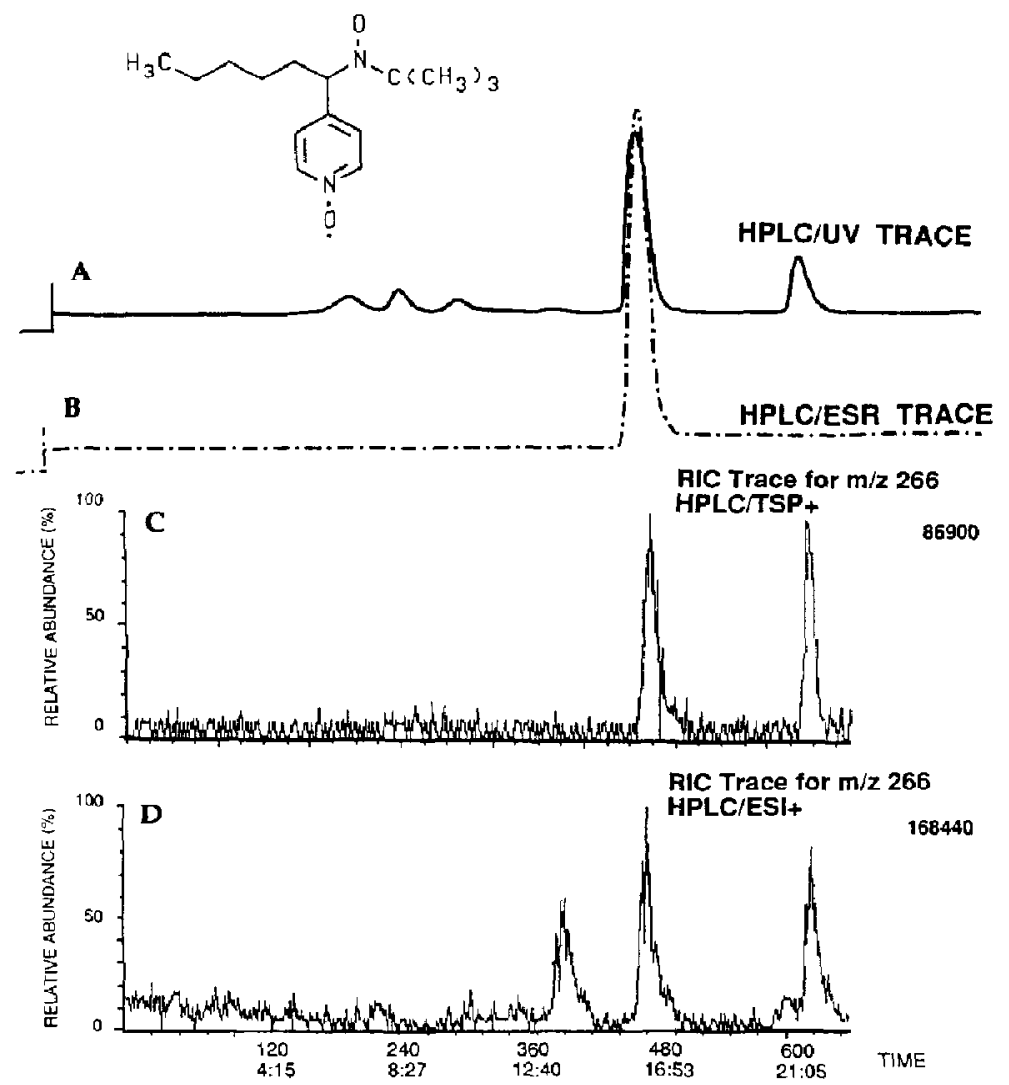

flow rate for ESI versus $1 \mathrm{~mL} / \mathrm{min}$ for TSP). For the POBN-ethyl radical, TSP gave a peak height approximately 3 times the peak height of the ESI molecular ion, as determined by the VG data system $(374,600$ counts by TSP versus 138,410 counts by ESI). For the POBN-pentyl radical, the peaks were actually a factor of 2 higher by ESI than by TSP $(86,900$ counts by TSP versus 168,440 counts by ESI). On the basis of the base peak in the spectra, however, the TSP spectrum is approximately 10 times more intense than is the ESI spectrum for both radicals. After correction for the 80:1 split, the ESI spectra are approximately 10 times
Figure 4. TSP and ESI mass spectra for the POBN-pentyl radical adduct (obtained from the HPLC-TSP-MS and HPLC-ESI-MS analyses shown in Figure 3).
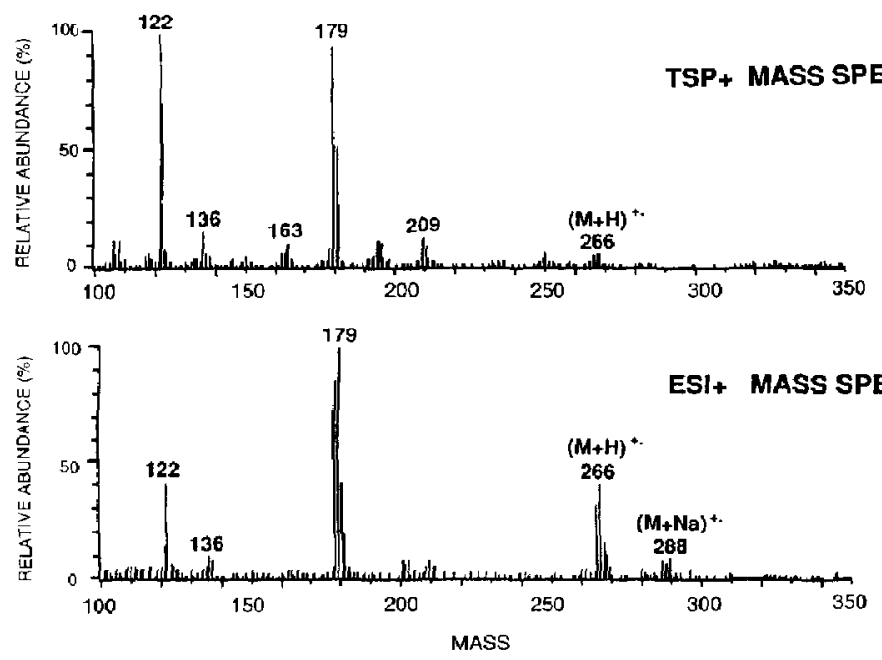

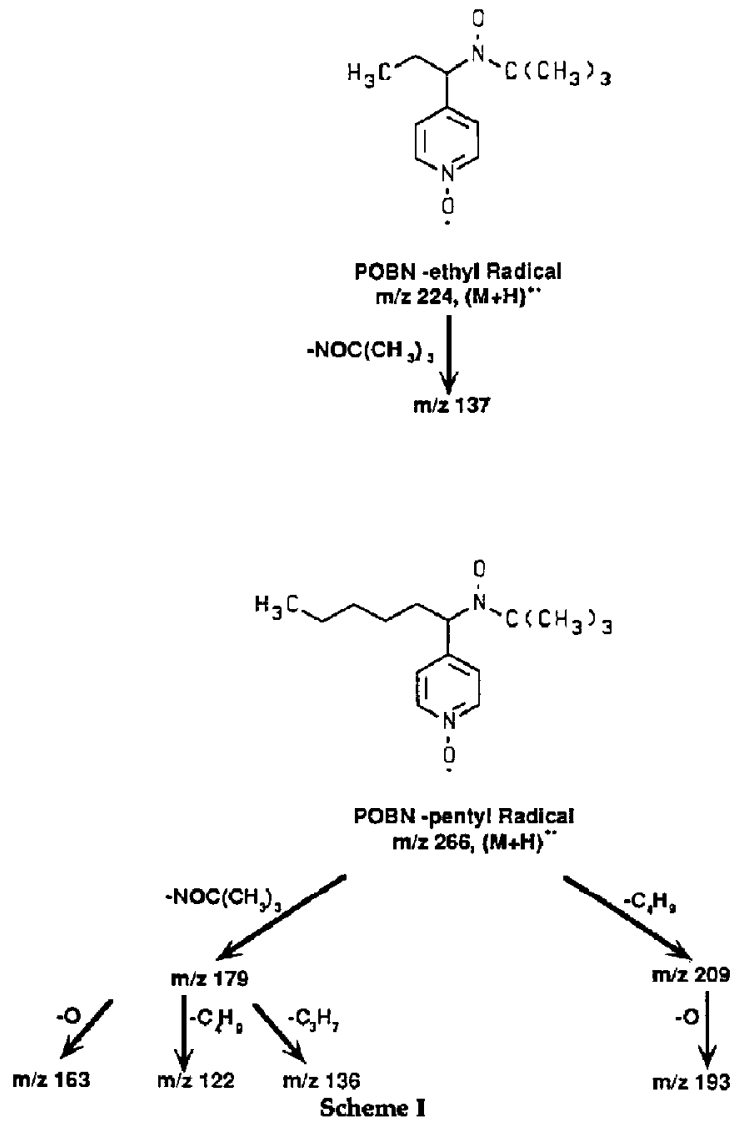

more sensitive than the TSP spectra. Because the absolute amount of the relatively unstable radical adduct being analyzed cannot be determined, the absolute sensitivity of the techniques cannot be determined. The detection limit for POBN itself by ESI, however, is approximately $10^{-3} \mathrm{M}(1.3 \mathrm{pm}, 250 \mathrm{pg}$ for a 2-s scan). This is in comparison to EPR, which has a typical detection limit for a POBN radical of about $10^{-7} \mathrm{M}$ (and requires ca. $0.1 \mathrm{~mL}$ of solution, $1 \mathrm{pm}$ total). In addition small, nonradical impurity peaks were also more readily detected by ESI than by TSP.

Given the necessity of splitting the column effluent for standard-bore HPLC columns in conjunction with ESI, the sensitivities of TSP and ESI are comparable in terms of the amount of analyte needed to be injected on column. Thus, in practical terms, there is no advantage to either technique except that material can be recovered from the ESI postcolumn split. If it were not necessary to match the retention times of the radical peak with that determined by HPLC-EPR, which requires $1 \mathrm{~mL} / \mathrm{min}$ flow rates, it would be feasible to use smaller HPLC columns. As ESI is reported to be a "concentration-dependent" detector, rather than a mass flow-dependent detector [34], a decreased mobile phase flow rate would lead to a higher analyte concentration in the mobile phase for the same amount of material injected on column and, thus, would yield better sensitivity.

\section{Conclusion}

The experiments above demonstrate the feasibility of using HPLC-ESI-MS for the determination and identification of spin-trapped radical adducts. This provides a powerful technique for the structure determination of relatively unstable spin-trapped radical adducts that has not been available previously.

\section{References}

1. Janzen, E. G.; Blackburn, B. J. J. Am. Chem. Soc. 1968, 90, 5909.

2. Hill, H. A. O.; Thornalley, P. J. FEBS Lett, 1981, 125, 235.

3. Sinha, B. K.; Motten, A. G. Biochem. Biophys. Res. Commun. 1982, 105, 1044.

4. Morrison, A.; Davies, A. P. Org. Mass Spectrom. 1970, 3, 353.

5. Noda, A.; Noda, H.; Ohno, K.; Sendo, T.; Misaka, A.; Kanazawa, Y.; Isobe, R.; Hirota, M. Biochem. Biophys. Res. Commun. 1985, 133, 1086.

6. Suezawa, H.; Abe, K.; Hirota, M.; Ishii, T. Chem. Lett. 1981, 1049.

7. Wanatabe, T.; Yoshida, M.; Fujiwara, S.; Abe, K.; Onoe, A.; Hirota, M+; Igarashi, S. Anal. Chem. 1982, 54, 2470.

8. Ortiz de Montellano, P. R.; Augusto, O.; Viola, F.; Kunze, K. L. J. Biol. Chem. 1983, 258, 8623.

9. Abe, K.; Suezawa, H.; Hirota, M. J. Chem. Soc. Perkin Trans. 1984, II, 29.

10. Mikame, N.; Takahashi, N.; Yamada, H.; Miyamoto, J. Pestic. Sci. 1985, 16, 101.

11. Krygsman, P. H.; Janzen, E. G.; Towner, R. A.; Haire, D. L. Anal. Lett. 1989, 22, 1009.

12. Iwahashi, H.; Albro, P. H.; McGown, S. R,; Tomer, K. B.; Mason, R. P. Arch. Biochem. Biophys. 1991, 285, 172.

13. Makino, K.; Hatano, H. Chem. Lett. 1979, 119.

14. Makino, K.; Moriyama, F.; Hatano, H. I. Chromatog. 1985. 332, 71

15. Iwahashi, H.; Ikeda, A.; Negoro, Y.; Kido, R. Biochem. I. 1986, 236, 509.

16. Sugata, R.; Iwahashi, H.; Ishii, T.; Ryo, K. I. Chromatog. 1989, 487, 9.

17. Iwahashi, H.; Parker, C. E.; Mason, R. P.; Tomer, K. B. Rapid Commun. Mass Spectrom. 1990, 4, 352.

18. Iwahashi, H.; Parker, C. E.; Mason, R. P.; Tomer, K. B. Biochem. J. 1991, in press.

19. Whitehouse, C. M.; Dreyer, R. N.; Yamashita, M.; Fenn, J. B. Anal. Chem. 1985, 57, 675.

20. Thompson, B. A.; Iribarne, J. V. J. Chem. Phys. 1979, 71. 4451.

21. Bruins, A. P.; Covey, T. R.; Henion, J. D. Anal. Chem. 1987, $59,2642$.

22. Loo, J. A.; Edmonds, C. G.; Smith, R. D.; Lacey, M. P.; Keogh, T. Biomed. Environ. Mass Spectrom. 1990, 19, 286.

23. Loo, J. A.; Edmonds, C. G.; Smith, R. D. Science 1996, 248, 201.

24. Chowdhury, S. K.; Katta, V.; Chait, B. T. Biochem. Biophys. Res. Commun. 1990, 167, 686.

25. Ikonomou, M. G.; Blades, A. T.; Kebarle, P. Anal. Chem. $1990,62,957$. 
26. Lee. E. D.; Mueck, W.; Henion, J. D.; Covey, T. R. Biomed. Environ. Mass Spectrom. 1989, 18, 844.

27. Quilliam, M. A.; Thompson, B. A.; Scott, G. J.; Siu, K. W. M. Rapid Commun. Mass Spectrom. 1989, 3, 145.

28. Pleasance, S.; Quilliam, M. A.; de Freitas, A. S. W.; Marr, J. C.; Cembella, A. D. Rapid Commun. Mass Spectrom. 1990. 4, 206.

29. Deterding, L. J.; Parker, C. E.; Perkins, J. R.; Moseley, M. A.; Jorgenson, J. W.; Tomer, K. B. J. Chromatog. 1991, in press.
30. Hershberger, L. W.; Callis, J. B.; Christian, G. B. Anal. Chem. 1979, 51, 1444.

31. Moseley, M. A.; Deterding, L. J.; Tomer, K. B.; Jorgenson, J. W. Anal, Chem. 1991, 63, 109.

32. Melera, A. Adv. Mass Spectrom. 1980, 8, 1597.

33. Augusto, O.; Beilan, H. S.; Ortiz de Montellano, P. R. O. I. Biol. Chem. 1982, 57, 11288.

34. Covey, T.; Shushan, B. Proceedings of the 38th Annual Conference of the American Society for Mass Spectrometry and Allied Topics, Tucson, AZ, June 3-8, 1990, p. 1148. 